\title{
Effect of disease severity on rheumatoid arthritis concordance in same sexed siblings
}

\author{
C M Deighton, D F Roberts, D J Walker
}

\begin{abstract}
To assess the factors in a proband with rheumatoid arthritis (RA) that might predict the occurrence of the disease in siblings, 240 same sexed sibships (190 female, 50 male) in which the proband had classical or definite RA were clinically and immunologically documented. Sibship concordance rates were consistently higher for features of severe disease in the proband, reaching statistical significance for a clinical score of disease severity (the SS index). This trend for increasing disease severity to be associated with increasing sibship concordance rates could not be accounted for by age or disease duration of the proband. These results suggest that siblings of probands with severe $R A$ are at greater risk of developing RA than those of probands with mild disease.
\end{abstract}

(Ann Rheum Dis 1992;. 51: 943-945)

Familial aggregation studies of rheumatoid arthritis (RA) have concluded that first degree relatives of RA probands have a small but definite increased risk of developing the disease. ${ }^{1}$ Approximately 2-3\% of RA probands have first degree relatives with $R A$, and in a small number of these families many members are affected. ${ }^{2}$ Is there any evidence that these multicase families are different from the more common sporadic occurrence of patients with RA? In the days before the HLA association with RA was discovered, Lawrence noted that RA probands who were seropositive and had erosive disease had much higher disease recurrence rates in first degree relatives than seronegative and nonerosive probands. ${ }^{3}$ Other studies have suggested that $R A$ probands with affected first degree relatives are more likely to be HLA-DR4 positive, ${ }^{45}$ and that HLA-DR4 positive subjects have more severe disease, ${ }^{6}$ so that familial RA might be predicted to be more severe than sporadic RA. Proband features associated with increased concordance rates for RA would be expected to be the result of shared genetic or environmental factors. Our previous study has shown RA concordance rates in same sexed siblings increasing from $5 \cdot 2 \%$ in subjects who did not have identical HLA types to $7 \cdot 1 \%$ in subjects with hemi-identical HLA types to $15.5 \%$ in subjects with identical HLA types. ${ }^{7}$ We were interested in studying other clinical and immunological factors of the proband that may affect the sibship disease concordance rate, and to determine if any associations between proband RA severity and disease familiarity could be explained in terms of confounders such as age and disease duration.
Patients and methods

The patient group used for this study has been described in detail previously. ${ }^{7}$ Briefly, 240 same sexed sibships ( 190 female and 50 male) in which the proband had classical or definite $\mathrm{RA}^{8}$ and at least one same sexed sibling living within 50 miles of Newcastle were consecutively recruited from rheumatology clinics in Newcastle upon Tyne and North Shields. Each member of the sibship was documented for the presence, severity, and distribution of RA using a clinical score (the SS index ${ }^{9}$ ) scoring each set of joints (distal interphalangeal joints, proximal interphalangeal joints, metacarpophalangeal joints, wrists,- elbows, shoulders, jaw, neck, lumbar spine, hips, knees, ankles and metatarsophalangeal joints) as $0=$ normal, $1=$ tender only, $2=$ swollen only, $3=$ tender and swollen, and $4=$ deformed or had been operated on. In asymmetrical disease the most affected side was scored. For sets of joints such as the distal interphalangeal joints, the worst affected joints were the ones that were scored for that group. The SS index score was calculated from the sum of the scores of all of the sets of joints. The duration of morning stiffness and any history of extra-articular disease manifestations were recorded. All subjects completed a health assessment questionnaire (HAQ) ${ }^{10}$ to indicate the level of disability. Hand radiographs taken within one year either side of the day that the patient was assessed were available for 225 patients, and were graded using a modified Larsen index scoring from 0 (normal) to 50 (severe multiple joint destruction). ${ }^{11}$ Blood samples were taken for the determination of IgM rheumatoid factor by the rheumatoid antibody haemagglutination test (Fugizoki Pharmaceutical, Tokyo, Japan) using rabbit IgG passively bound to gelatin particles. Antinuclear antibodies were detected by a standard indirect immunofluorescent technique using Wellcome fluorescein isothiocyanate antihuman immunoglobulin for labelling.

For each proband, a percentage concordance rate was calculated from the number of affected siblings divided by the total number of siblings (excluding the proband). The mean sibship concordance rate was the mean of all the individual sibship concordance rates. The rationale for this analysis has been described previously. ${ }^{7}$ For this analysis, only siblings with classical or definite disease have been included.

For continuous variables such as proband age and SS index, values were arranged in ascending order and arbitrarily divided into tertiles. For each tertile an overall mean sibship concordance rate was calculated. Odds ratios for the prediction of the mean sibship concordance rates 
Table 1 Distribution of mean sibship concordance rate (MSCR) and unadjusted odds ratios for ascending age and disease duration groups

\begin{tabular}{|c|c|c|c|}
\hline Patient group & $\begin{array}{l}\text { Number of } \\
\text { probands }\end{array}$ & MSCR (\%) & $\begin{array}{l}\text { Odds ratio } \\
\left(95 \%(C I)^{*}\right.\end{array}$ \\
\hline $\begin{array}{l}\text { Age group (years) } f \\
<54 \\
54-62 \\
>62\end{array}$ & $\begin{array}{l}82 \\
82 \\
76\end{array}$ & $\begin{array}{r}5 \cdot 4 \\
9 \cdot 2 \\
11 \cdot 7\end{array}$ & $\begin{array}{l}1 \cdot 0 \\
1.9(0 \cdot 8,4 \cdot 5) \\
2 \cdot 1(0 \cdot 9,5 \cdot 1)\end{array}$ \\
\hline $\begin{array}{l}\text { Disease duration } \\
\text { group (years) } ¥ \\
<6 \\
6-14 \\
>14\end{array}$ & $\begin{array}{l}87 \\
76 \\
77\end{array}$ & $\begin{array}{r}4 \cdot 2 \\
14 \cdot 1 \\
8 \cdot 4\end{array}$ & $\begin{array}{l}1 \cdot 0 \\
2 \cdot 8(1 \cdot 1,6 \cdot 8) \\
1 \cdot 8(0 \cdot 7,4 \cdot 5)\end{array}$ \\
\hline
\end{tabular}

${ }^{*} \mathrm{CI}=$ confidence interval.

TTest for trend in odds ratios, $0.05<\mathrm{p}<0.1$.

$\neq$ Test for trend in odds ratios, $p>0.02$.

Table 2 Distribution of mean sibship concordance rate (MSCR) and unadjusted odds ratios for ascending $S S$ index, modified Larsen $x$ ray grading, and health assessment questionnaire (HAQ) scores

\begin{tabular}{|c|c|c|c|}
\hline $\begin{array}{l}\text { Measure of } \\
\text { disease severity }\end{array}$ & $\begin{array}{l}\text { Number of } \\
\text { probands }\end{array}$ & MSCR (\%) & $\begin{array}{l}\text { Odds ratio } \\
\left(95 \%(C I)^{*}\right.\end{array}$ \\
\hline $\begin{array}{l}\text { SS index scoret } \\
<14 \\
14-21 \\
>21\end{array}$ & $\begin{array}{l}76 \\
83 \\
81\end{array}$ & $\begin{array}{r}5 \cdot 4 \\
4 \cdot 9 \\
15 \cdot 8\end{array}$ & $\begin{array}{l}1.0 \\
0.9(0.3,2.6) \\
2.5(1.0,6.0)\end{array}$ \\
\hline $\begin{array}{c}x \text { Ray grading score } \neq \\
<16 \\
16-27 \\
>27\end{array}$ & $\begin{array}{l}66 \\
70 \\
69\end{array}$ & $\begin{array}{r}4 \cdot 8 \\
6 \cdot 4 \\
12 \cdot 2\end{array}$ & $\begin{array}{l}1.0 \\
1.0(0.2,4 \cdot 1) \\
1.8(0.7,4 \cdot 6)\end{array}$ \\
\hline $\begin{array}{l}\text { HAQ score } \oint \\
<1 \cdot 4 \\
1 \cdot 4-2 \cdot 1 \\
>2 \cdot 1\end{array}$ & $\begin{array}{l}85 \\
71 \\
84\end{array}$ & $\begin{array}{r}3 \cdot 6 \\
16 \cdot 4 \\
7 \cdot 4\end{array}$ & $\begin{array}{l}1 \cdot 0 \\
4 \cdot 4(1 \cdot 6,11 \cdot 6) \\
2 \cdot 5(0.9,6 \cdot 7)\end{array}$ \\
\hline
\end{tabular}

${ }^{*} \mathrm{CI}=$ confidence interval.

+ Test for trend in odds ratios, $\mathrm{p}<0.025$.

$\neq$ Test for trend in odds ratios, $p=0 \cdot 1$.

ITest for trend in odds ratio, $p=0 \cdot 1$.

Table 3 Distribution of mean sibship concordance rate (MSCR) and odds ratios with respect to rheumatoid and antinuclear factor antibody

\begin{tabular}{|c|c|c|c|}
\hline Titre & $\begin{array}{l}\text { Number of } \\
\text { probands }\end{array}$ & MSCR (\%) & $\begin{array}{l}\text { Odds ratio } \\
(95 \% \text { CI })^{*}\end{array}$ \\
\hline $\begin{array}{l}\text { Rheumatoid factort } \\
0-1 / 40 \\
1 / 80-1 / 160 \\
>1 / 160\end{array}$ & $\begin{array}{l}64 \\
68 \\
94\end{array}$ & $\begin{array}{l}6 \cdot 7 \\
9 \cdot 7 \\
8 \cdot 2\end{array}$ & $\begin{array}{l}1.0 \\
1.3(0.5,3.6) \\
1.2(0.5,3.0)\end{array}$ \\
\hline $\begin{array}{l}\text { Antinuclear antibodies } \neq \\
0 \\
1 / 10-1 / 20 \\
>1 / 20\end{array}$ & $\begin{array}{r}112 \\
56 \\
72\end{array}$ & $\begin{array}{r}5 \cdot 2 \\
7 \cdot 1 \\
15 \cdot 4\end{array}$ & $\begin{array}{l}1.0 \\
0.9(0.3,2.5) \\
2 \cdot 1(0.9,4.8)\end{array}$ \\
\hline
\end{tabular}

${ }^{*} \mathrm{CI}=$ confidence interval.

TTest for trend in odds ratio, $p>0.2$.

$\neq$ Test for trends in odds ratio, $p=0 \cdot 1$.

Table 4 Distribution of mean sibship concordance rates (MSCRs) for the presence and absence of extra-articular disease manifestations

\begin{tabular}{|c|c|c|c|}
\hline \multirow[t]{2}{*}{ Extra-articular feature } & \multicolumn{2}{|l|}{ Overall $M S C R$} & \multirow{2}{*}{$\begin{array}{l}\text { Unadjusted odds } \\
\text { ratio }\left(95 \%(I)^{*}\right.\end{array}$} \\
\hline & $\begin{array}{l}\text { Feature present } \\
\text { [\% (no of patients)] }\end{array}$ & $\begin{array}{l}\text { Feature absent } \\
\text { [\% (no of patients)] }\end{array}$ & \\
\hline $\begin{array}{l}\text { Nodules } \\
\text { Vasculitis } \\
\text { Dry eyes }\end{array}$ & $\begin{array}{l}10.4(87) \\
14.8(9) \\
13.0(83)\end{array}$ & $\begin{array}{l}7 \cdot 8(153) \\
8 \cdot 5(231) \\
6 \cdot 5(157)\end{array}$ & $\begin{array}{l}1.2(0.6,2.5) \\
1.6(0.7,2.9) \\
1.5(0.7,2.9)\end{array}$ \\
\hline
\end{tabular}

${ }^{*} \mathrm{CI}=$ confidence interval.

Table 5 Spearman's rank correlation coefficients between age and disease duration of proband and measures of disease severity

\begin{tabular}{lll}
\hline $\begin{array}{l}\text { Measure of } \\
\text { disease severity }\end{array}$ & Age & $\begin{array}{l}\text { Disease } \\
\text { duration }\end{array}$ \\
\hline SS index score & 0.25 & 0.52 \\
Modified Larsen $x$ ray grading & 0.32 & 0.56 \\
HAQ score* & 0.29 & 0.54 \\
\hline
\end{tabular}

All values are significant at $p<0.001$.

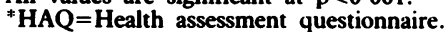

were calculated using a logistic regression analysis, with the ratio of 1.0 assigned to the first tertile. With reference to this value, odds ratios with $95 \%$ confidence intervals were calculated for the second and third tertiles. A test for statistically significant trends in the odds ratio was calculated. Any continuous variables that showed a significant trend with the mean sibship concordance rates had odds ratios recalculated, having adjusted for potential confounders such as the age of the proband.

\section{Results}

Table 1 shows the influence of the age and disease duration of the proband on the mean sibship concordance rate. As age increased there was a gradual increase in the overall mean sibship concordance rate and in the odds ratios. This was narrowly outside conventional significance levels on testing for trends in odds ratios. For disease duration, the highest mean sibship concordance rate was in the middle age group. Not surprisingly, a test for trends was not significant.

Table 2 shows measures of disease severity. The radiographic grading scores showed an increasing mean sibship concordance rate with increasing severity. For the SS index, the mean sibship concordance rates were similar in the first two severity groups, with that in the second slightly lower than the first. Despite these observations, a test for trends in odds ratios was significant for the SS index, but narrowly failed to reach significance for the radiographic grading and $H A Q$ scores.

As a result of the possible influence of the age of the proband on disease severity and sibship concordance, logistic regression analysis was used to calculate odds ratios for siblings of probands affected by RA for the SS index after adjusting for the age of the proband. The odds ratios of the second and third SS index groups were 0.9 and 2.3 respectively. This showed little or no change from the first odds ratios (see table 2) and the test for trend remained significant.

Tables 3 and 4 show the associations between mean sibship concordance rate and rheumatoid factor, antinuclear factor, and extra-articular disease manifestations. Increasing titres of rheumatoid factor failed to show any association with the mean sibship concordance rate. There was a tendency for increasing antinuclear antibody titres to be associated with increasing mean sibship concordance rates, though the test for trends in odds ratios was not significant. The possession of nodules, vasculitis, and the regular use of artificial teardrops were all associated with higher mean sibship concordance rates, though the odds ratios of these probands having affected siblings were not significant.

Logistic regression was used to estimate the amount of variance that could be accounted for by some of these variables in the prediction of the mean sibship concordance rate. Combining the SS index with the radiographic grading, HAQ scores, and the antinuclear antibody titres only accounted for $11 \cdot 1 \%$ of the variance of the mean sibship concordance rates. 
Discussion

We have previously shown that HLA haplotype sharing and sex have an influence on the presence and expression of RA. Female sex and the sharing of both HLA haplotypes with the proband were associated not only with a higher occurrence of RA, but also a tendency for the RA to satisfy classical or definite, as opposed to probable, RA according to 1958 American Rheumatism Association criteria. ${ }^{7}$ This work addresses other important risk factors in the development of RA by investigating the influence of markers of disease severity on the mean sibship concordance rate for RA in same sexed sibships.

A potential biasing factor in the calculation of mean sibship concordance rates is the age of the proband. As RA can start at any time in life, an increase in disease concordance rates might be expected with increasing age of the proband. Furthermore proband age and particularly disease duration might be expected to influence disease severity. These variables were not considered in the study of Lawrence, which showed higher first degree relative concordance rates in RA probands with severe disease. ${ }^{3}$ The present study showed that there was. no significant trend between increasing proband age or disease duration and mean sibship concordance rate. As odds ratios for the former narrowly failed to reach significance, however, these were calculated for the SS index and mean sibship concordance rates before and after adjusting for age. This made little difference to the odds ratios suggesting that age is not a major influence on the association between proband disease severity and sibling concordance rates. Furthermore the correlation coefficients in table 5 show that disease duration was more highly correlated with disease severity than age. As disease duration showed no association with mean sibship concordance rate, and age only a trend, this reinforces the conclusion that whatever factors determine the severity of RA (particularly as measured by the SS index), these are more important in predicting the mean sibship concordance rate than age or disease duration.

The general tendency was for more severe disease to be associated with higher mean sibship concordance rates, though this only reached conventional significance for the SS index. Factors previously associated with more severe disease showed a variable, though broadly similar, tendency. High titres of rheumatoid factor are associated with more severe $R^{12}{ }^{13}$ and extra-articular disease. ${ }^{14}$ Patients positive for antinuclear factor tend to have more severe RA with more extra-articular features. ${ }^{14}$ Seropositive RA has been associated with higher disease concordance rates than seronegative RA in other papers. ${ }^{3}$ These data suggest, however, that high titres of antinuclear antibodies in the proband are a better predictor (albeit weak) of familial RA than high titres of rheumatoid factor. In keeping with the antinuclear factor observation, the presence of nodules, vasculitis, and regular use of artificial teardrops were all associated with higher mean sibship concordance rates, though none of these showed a significant odds ratio.

The amount of variance of the mean sibship concordance rate accounted for by the measures of disease severity used here was small, suggesting that RA disease severity is a weak predictor of higher mean sibship concordance rates. This is compatible with a multifactorial threshold model of RA, in which an accumulation of the influence of several genetic and environmental factors in the same subject might predispose to severe RA and a higher disease prevalence in siblings sharing some or all of these factors. There is evidence to suggest that HLA-DR4 is associated with disease severity ${ }^{12}$ and a familial disease propensity. ${ }^{4}$ Further research is needed to determine what other genetic and environmental factors predispose to severe and familial RA.

This work was supported by the Arthritis and Rheumatism Council. We thank Paul Brennan of the Arthritis and Rheumatism Council Epidemiology Research Unit at the University of Manchester for help and advice with the statistical analysis. We thank Dr A Fay of the Department of Immunology, Newcastle General Hospital, for the autoantibody results. We thank Dr J General Hospital, for the autoantibody results. We thank Dr J
Wentzel of the Department of Human Genetics, University of Newcastle upon Tyne, and Mr G Cavanagh of the Regional Blood Transfusion Service, for the HLA typing.

1 Deljunco D J, Luthra H S, Annegers J F, Worthington J W, Kurland $\mathrm{L}$ T. The familial aggregation of rheumatoid arthritis and its relationship to the HLA DR4 association. Am 7 Epidemiol 1984; 119:-813-27.

2 Deighton C M, Walker D J. The familial nature of rheumatoid arthritis. Ann Rheum Dis 1991; 50: 62-5.

3 Lawrence J S. Rheumatoid arthritis-nature or nurture? Ann Rheum Dis 1970; 29: 357-79.

4 Sanders P A, Grennan D M, Dyer P A, Thomson W, de Lange G G. A comparison of clinical and immunogenetic features in familial and sporadic rheumatoid arthritis. f Rheumatol 1987; 14: 718-22.

5 Khan M A, Khan M K. HLA studies in familial and sporadic RA. Dis Markers 1986; 4: 67-76.

6 Van Zeben D, Hazes J $M$ W, Zwinderman A H, et al. Association of HLA-DR4 with a more progressive disease course in patients with rheumatoid arthritis. Arthritis Rheum 1991; 34: 822-30.

7 Deighton C M, Wentzel J, Cavanagh G, Roberts D F, Walker D J. Contribution of inherited factors to rheumatoid arthritis. Ann Rhewm Dis 1992; 51: 182-5.

8 Ropes M W, Bennett G A, Cobb S, Jacox R, Jessar R A. Revision of diagnostic criteria for rheumatoid arthritis. Bull Rheum Dis 1958; 9: 175-6.

9 Walker D J, Griffiths M, Dewar P, et al. Association of MHC antigens with susceptibility to and severity of rheumatoid arthritis in multicase families. Ann Rheum Dis 1985; 44: arthritis

10 Kirwan J R, Reeback J S. Stanford health assessment questionnaire modified to assess disability in British patients with rheumatoid arthritis. Br $\mathcal{J}$ Rheumatol 1986, 25: 206-9.

11 Walker D J, Griffiths I D. HLA association are with severe rheumatoid arthritis. Dis Markers 1986; 4: 121-32.

12 Calin A, Elswood J, Klouda P T. Destructive arthritis, rheumatoid factor, and HLA-DR4: suspectibility versus severity, a case-control study. Arthritis Rheum 1989; 32: 1221-5.

13 Buchanan $W W$, Singal D P. Is there a need to reclassify adult rheumatoid arthritis? Br $\mathcal{F}$ Rheumatol 1990; 29: 377-82.

14 Erhardt C C, Mumford P A, Venables P J W, Maini R N. Factors predicting a poor life prognosis in rheumatoid arthritis: an eight year prospective study. Ann Rheum Dis 1989; 48: 7-13. 